\title{
Emerging strategies in radiation countermeasure research
}

\begin{abstract}
Radiation threat perceptions have seen an increase in recent times. Since much of the current understanding of radiation biology has come from nuclear accidents, this short communication briefly takes stock of the major/minor radiation fallouts in last three decades in terms of the type/amount of radioactive nuclide dissemination, which causes the internal/external biologic contamination, causalities, environmental issues and level of public awareness and preparedness towards it. Also, it highlights the ill effects of increased use of diagnostic ionizing radiation. The paper recaps the evolution of radioprotectors and mitigators from initial sulfhydryl compounds to the present- natural antioxidants and biologic cell response modifiers. From these, the emerging strategies in radiation counter measures: training for rescuers, biodosimetry for absorbed doses, development of new radiation decontamination devices/products and the shift towards combination radiotherapy using bio resources/biomimetic/ stem cell approaches, with minimal toxicity are touched upon. Beneficial spin-offs like thyroid disease treatment, radiopharmaceutical mediated molecular imaging and innovative development of lead free radiation deterrent materials for diagnostic radiology are also mentioned. Overall, it presents a road map for better management of radiation insults.
\end{abstract}

Keywords: radiation countermeasure, radioprotector, mitigator, lead free radiation shields
Volume 4 Issue $6-2017$

\author{
Manu Krishnan,' Ajay Kumar Singh² \\ 'Department of Dental Research \& Implantology, Institute of \\ Nuclear Medicine and Allied Sciences (INMAS), India \\ ${ }^{2}$ Institute of Nuclear Medicine and Allied Sciences (INMAS), \\ India
}

Correspondence: Manu Krishnan, Department of Dental Research \& Implantology, Institute of Nuclear Medicine and Allied Sciences (INMAS), Defence Research and Development Organization (DRDO) Ministry of Defence, Govt of India, Timarpur, Delhi, India, Tel 0 I I 23939588, 886082 I 484, Email manuseemal3@gmail.com

Received: December 09, 2017 | Published: December 14, 2017

\begin{abstract}
Abbreviations: NMR, nuclear magnetic resonance; IAEA, international atomic energy agency; CBRN, chemical biologic radiologic and nuclear; CDKs, cyclin dependent kinases; ICRP, international commission on radiological protection; ARS, acute radiation syndrome; ROS, reactive oxygen; RNS, nitrogen species
\end{abstract}

\section{Introduction}

The colossal damages inflicted to the humanity by the Hiroshima and Nagasaki atom bombings during Second World War (1945) prompted radiation countermeasure research world over. The recent global and regional geopolitical scenario embroiled with terrorism has escalated the nuclear threat perception among all concerned. Radiation exposure is a natural event occurring from the sun and radioactive elements in the earth. Some amount of radiation exposure happens during diagnostic imaging also. However; in higher doses, it is toxic to living tissues because (i) it ionizes biological molecules and (ii) generates free radicals like reactive oxygen/nitrogen species (ROS/RNS) in the cells. The ensuing DNA/protein damage, lipid peroxidation and cellular oxidative stress perpetuate multisystem damages. ${ }^{1}$ Radiation accidents have therefore questioned the conventional presumptions in dealing with human disasters in terms of the mortality, morbidity, mutations, food safety and environmental repercussions it poses. Nuclear warfare is fortunately less frequented. Hence, an audit of probable future nuclear fallouts is mostly based on the knowledge gained from industrial accidents: leakage of radiation either from nuclear power plants or radioactive cargo during transit and by the inadvertent exposure from radioactive debris. ${ }^{2}$ In light of all these, this article examines the current understanding, future strategies, therapeutic spin-offs and innovations in radiation countermeasure pursuits.

\section{Radiation exposure experiences in last three decades (1986-2016)}

Chernobyl nuclear accident happened on 26 April 1986 in the Lenin Chernobyl Nuclear Power Plant, releasing large volumes of uranium dioxide fuel and fission products over Russia, Europe and some parts of Asia and Canada. Accident had a 50\% lethal dose (LD50) at $6 \mathrm{~Gy}$ and a total global effective dose of $6,00,000 \mathrm{~Sv}$. Thyroid doses in this prefecture were $20-1000$ milliSv for adults and $20-6000 \mathrm{mSv}$ for infants. So, immediate concern was of thyroid cancer due to I-131 with a half life of 8 days. Long term issues of environmental contamination were by strontium-90 and cesium-137 (half life of 30 years). Number of deaths was around 4000 . Thyroid cases in 2006; 20 years after the accident were over 10000 , with future predictions of 50,000. ${ }^{3}$ Fukushima Daiichi Nuclear Power Plant accident in Tohoku, Japan happened on 11 March 2011 following Richter scale-9 earthquake, Tsunami and floods. ${ }^{4}$ This released radioactive nuclides I-131 (160PBq), Cs-134 and Cs-137 (15-18PBq). Both Fukushima and Chernobyl accidents were scaled to 7 as per International Nuclear and Radiological Event grading. ${ }^{3}$ In a small incident in March-April 2010, a Cobalt-60 irradiator from a scrap yard in Delhi, India, caused radiation injury to seven persons and one death due to acute radiation syndrome (ARS). LD50 of the deceased was 3.1Gy. Rest of the seven also had ARS, but was saved with medical management. ${ }^{5}$ Ionizing radiation emanating from all these; major and minor accidents, causes dreadful disease states, death and environmental hazards. Pathways of radiation exposure to humans are from radionuclides deposited on the ground (ground shine), radioactive cloud (cloud shine), inhalation and ingestion through food and water. ${ }^{6-9}$ In short, nuclear reactor accidents cause: "Nuclear war without war". Major radiation accidents reported world over is shown in Figure 1. The break of radiation accidents 
illustrate the major contributions from radiotherapy (32\%) and fluoroscopy (31\%) followed by industrial $(27 \%)$ and others. The effects of 'internal' as well as 'external' exposure/contamination form the basis of radiation protection standards given by the International Commission on Radiological Protection (ICRP). On the contrary, accidents also reveal some natural radiation surviving mechanisms like black fungus, Cryptococcus neoformans and Cladosporium isolated from nuclear reactor core walls, demonstrating ability of melanin to absorb radiation energy. ${ }^{10}$
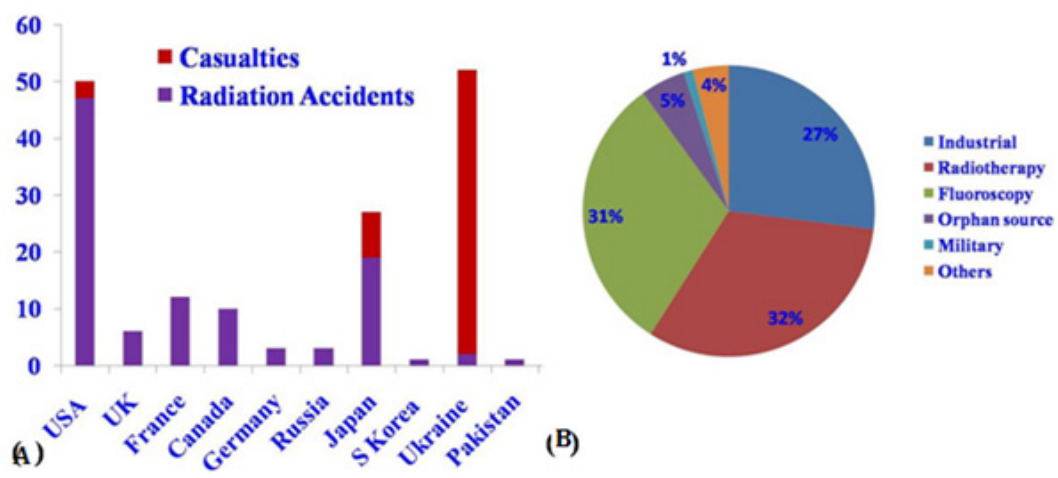

Figure I Radiation accidents and break up. (A) Accidents and casualties - country wise and (B) break up of accidents.

Radiation countermeasures: current status of radioprotectors and mitigators

Radioprotectors are prophylactic agents administered prior to or at the time of radiation exposure, while mitigators are given after radiation and are expected to facilitate DNA repair and apoptosis of damaged cells, reduce oxidative stress and related inflammation. ${ }^{11}$ Radioprotectives so far developed have been predominantly derivatives of 'sulfhydryl groups'- amino thiols, amino disulphides, di-thio-carbamates, cysteine, mercapto-ethylamine etc. They are twothree carbon chain compounds with a sulfhydryl group and amino group at both ends. Amifostine/WR2721/[S-2-(3-aminopropylamino) ethyl phosphoro-thioic acid], the first to be FDA approved was developed by the Medical Research and Development Command of the American army in the late 1950s as part of its anti-radiation drug development program at the Walter Reed Army Research Center, Maryland. Amifostine undergoes de-phosphorylation by alkaline phosphatase and becomes an active sulfhydryl compound (WR 1065); with easy cell permeability for free radical scavenging. Since alkaline phosphatase is less expressed in tumor cells, risk of tumor protection was not there. ${ }^{12,13}$ Even though it went to phase III trials in reversing mucositis, xerostomia, dysphagia, pneumonitis and dermatitis, its side effects such as nausea, vomiting, hypotension and neurotoxicity outweighed the benefits and therefore is now not being used as a radioprotector. ${ }^{14}$ Similar to sulfhydryls, nitroxide free radicals and their reduction products- hydroxylamines are another group currently being investigated, where Tempol (4-hydroxy-2, 2, 6, 6-tetra methyl piperidine-1-oxyl) is a representative. ${ }^{12}$ Nonetheless; therapeutic efficacy of all these, are yet to be ascertained.

A different approach on radioprotection is based on 'natural antioxidants' and 'biologic cell response modifiers'. They include biomolecules like superoxide dismutase, glutathione peroxidase/ reductase, retinols, tocopherols, ascorbic acid, growth factors, cytokines, immunomodulators, polypeptides, cell cycle regulators like cyclin dependent kinases (CDKs), tumor suppressor genes (p53), and hormones like melatonin. Nevertheless, their efficacy is proven only in low dose radiation scenarios where reasonable amount of viable host cells are available post exposure. Their ability to scavenge secondary species of free radicals that elicit DNA damages is also limited. Further, there is a likelihood of tumor protection through nonselective free radical scavenging. ${ }^{13,15,16}$ A summary of all these agents and molecules are in Table $1 \& 2$.

Table I Radiation countermeasures-current status of radioprotectors/mitigators

\begin{tabular}{lll}
\hline S. no & Radioprotectors & Mechanism of action \\
\hline I & WR272I & Free radical scavenging \\
2 & $\gamma$-tocotrienol & Reversal of radiation induced hematopoietic syndrome \\
3 & Filgrastim & Reversal of hematopoietic, gastrointestinal and testicular dysfunctions \\
4 & Genistein & free radical scavenging and reduce oxidative stress and DNA damage
\end{tabular}

\section{Herbal radioprotectors with definitive mechanism of action}

I Podophyllum hexandrum Topoisomerase inhibitor

2 Hippophae rhamnoides Reduce-DNA damage, chromosomal aberrations, free radical scavenging and protection against hematopoietic syndrome 3 Ocimum sanctum $\quad \begin{aligned} & \text { Antioxidant activity, protection against liver lipid peroxidation, free radical scavenging, and metal } \\ & \text { chelation }\end{aligned}$

Herbal radioprotectors with non specific mechanism of action

I Tinospora cardiofolia 
Table Continued..

Herbal radioprotectors with non specific mechanism of action

$2 \quad$ Zingiber officinale

3 Rhodulla embricata

$4 \quad$ Gingko biloba

5 Amaranthus pamiculatus

6 Mentha arvensis

\section{Radiation mitigators}

$\begin{array}{lll}\text { I } & \begin{array}{l}\text { Histone Deacetylase } \\ \text { inhibitors }\end{array} & \text { Enhance DNA repair } \\ 2 & \text { Sulforaphane } & \text { Reduce radiation induced micronuclei formation in lymphocytes } \\ 3 & \text { Diallyl Sulphide } & \text { Enhance lymphocyte count } \\ 4 & \text { Epigallocatechin-3-gallate } & \text { Protect DNA breaks, lipid peroxidation reduce apoptosis in intestinal crypts }\end{array}$

Table 2 Radiation countermeasures: alternate approaches

\begin{tabular}{lll}
\hline \multicolumn{2}{l}{ Alternate approaches in reversing radiation induced cell damages } \\
\hline & Apoptosis blocking through kinase inhibitors \\
\hline & Down regulation of pro-apoptotic genes through siRNAs in nanoparticles \\
2 & Gene therapy & Growth factor (IGFI, KGF, FGF) mediated apoptosis inhibition \\
3 & Reversal of radiation induced accelerated senescence & Inhibition of mTOR \\
4 & Water channel proteins & Regulation of aquaporins (AQPI,AQP3,AQP5 and AQP8) \\
5 & Biomimetics & Lepidopteran insect cell simulations \\
6 & Progenitor and stem cell activation &
\end{tabular}

\section{Compounds/molecules in different stages of development as radioprotectors and mitigators}

Phosphoinositol - 3-kinase inhibitors, Fibroblast growth factor peptides, Somastatine, Captopril and ACE inhibitors, Insulin growth factors, Pallifermin, Cesium oxide nanoparticles, N acetyl cysteine, Tocopherol succinate, Indralin, Melatonin, Sesamol, Trichostatin, Diallyl sulphide, Rutin, Semiquinone glucoside derivatives, N acetyl tryptophan glucoside, G-CSF Granulocyte colony stimulating factor, GM-CSF Granulocyte monocyte colony stimulating factor.

\section{US - FDA investigative new drug (IND) status: drugs and manufacturers}

$\begin{array}{lll}\text { I } & \text { HemaMax/NMILI2-I } & \text { Neumedicine Inc } \\ 2 & \text { BI03000/Genistein } & \text { Humanities Pharmaceuticals } \\ 3 & \text { Orbishiled/BOP } & \text { Soligenix Inc } \\ 4 & \text { Androstenediol (5-AED) } & \text { Hollis-Eden Pharmaceuticals } \\ 5 & \text { G-CSF/Neupogen } & \text { Amgen Inc } \\ 6 & \text { GM-CSF/Sargramostin } & \text { Sanofi -Aventis } \\ 7 & \text { ONDI2I0/ExRad } & \text { Onconova Therapeutics } \\ 8 & \text { CBLB502/Entolimod } & \text { Cleveland Biolabs Inc } \\ \text { Drugs in advanced stages of development } & \\ \text { I } & \text { Gamma Tocotrienol (GT3) } & \text { AFRR/Heny M Jackson Foundation } \\ 2 & \text { AEOL I0I50 } & \text { Aeolus Pharmaceuticals Inc } \\ 3 & \text { Myeloid Progenitor Cells (MPC/CLT-008) } & \text { Cellerant Therapeutics }\end{array}$




\section{Radiation countermeasures: emerging stra- tegies}

The nuclear accidents and radioprotective research hitherto pursued have brought out several important lessons. There is a perceptible level of ill-preparedness and knowhow from first responders to personnel at different levels, in the nuclear rescue team. Since an ideal radioprotective agent has so far remained elusive, need for a paradigm shift in the approach towards radioprotective research is in the offing. Accordingly, the upcoming strategies in radiation countermeasures would have several components (Figure 2).

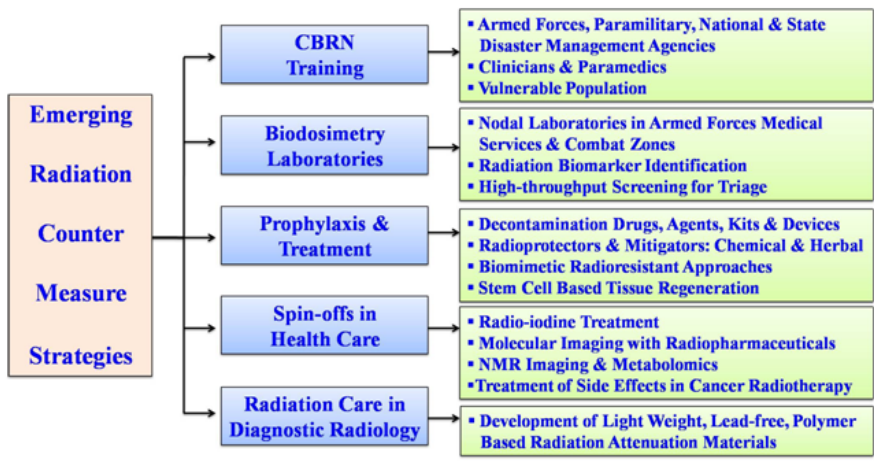

Figure 2 Components of emerging radiation countermeasure strategies.

\section{Chemical biologic radiologic and nuclear (CBRN) training and biodosimetry laboratories}

Training programs for improving the competency in radiation accident response by all stakeholders is central to this. Preparedness would also depend on the immediate assessment of 'absorbed doses' of affected population. 'Radiation biodosimetry labs' devised as per International Atomic Energy Agency (IAEA) recommendations would have an important role here to facilitate effective networking and in handling large number of samples. ${ }^{17}$ This needs to be augmented with human patient simulators, mobile whole body counters and radiochemical analytical facilities for triaging radiation victims.

\section{Prophylaxis and treatment}

Another key area would be decontamination wipes/kits, improvised protective clothing and other accessories for first responders. Pharmacologic compounds like complexones, cyanides/nerve gas antidotes, agents for radioactivity decorporation in nuclear accidents/ bomb scenarios are also essential to it. Considering the urgent need for inexpensive, widely available and easily administered radioprotective drugs with minimal side effects for large population, current focus in this area has been towards herbal sources or regeneration of radiation damaged tissues using 'stem cells' ${ }^{18}$ Since radiation injury initiates a multisystem response, the emerging theme would be for combination radioprotector therapy.

\section{Spin-offs in health care from radiation research}

Important spin-offs have been radioiodine treatment for thyrotoxicosis and thyroid cancer. Cyclotron based synthesis of novel radiopharmaceuticals, magnetic resonance contrast agents and nuclear magnetic resonance (NMR) based metabolomics would be other related advancements. Vis-a-vis nuclear accidents, radiotherapy for cancer treatment represents controlled exposure of radiation for killing malignant cells. Acute and chronic toxicities of normal tissues during radiotherapy are still an unresolved clinical issue. ${ }^{12}$
Implicitly, efforts to repeal the side effects of cancer radiotherapy on normal cells would be a primary target for all the currently researched radioprotectors and mitigators.

\section{Effects of diagnostic radiation and development of lead free radiation deterrent materials}

Though less in volume, diagnostic imaging is another facet of radiation exposure. Average yearly medical radiation dose was about $0.5 \mathrm{mGy} /$ person in the United States in 1982, which rose to $3.0 \mathrm{mGy} /$ person in 2006. The 2007 ICRP estimates have shown an increase of $32-422 \%$ in the radiosensitivity of the head and neck area with special impetus to thyroid gland. ${ }^{19}$ Hence protection of thyroid gland, which has higher propensity for malignant changes with external radiation, has greater relevance in contemporary diagnostic radiology. Considering the toxic/environmental/operator issues of lead; research and development of lead free, alternate radiation attenuation materials is one forthcoming approach. ${ }^{20}$ These materials may have applications not only in diagnostic radiology but also in making light weight antiradiation suits in nuclear warfare and deep space missions.

\section{Conclusion}

Future radiation countermeasure strategies would involve multiple approaches. Rapid biodosimetry is the foremost along with training for rescue teams and development of radiation de corporation drugs/ devices for prompt casualty evacuation. Radiation prophylaxis using potassium iodide and protection of radiosensitive organs like thyroid gland during diagnostic radiology should be given priority considering the propensity for malignant changes after radiation exposure. Radio protective research in the future is likely to show a swing towards combination therapy, preferably from biologic sources to minimize toxicities with enhanced competency in managing ARS. Mitigating cancer radiotherapy side effects shall be a testing ground for such novel radio protectors.

\section{Acknowledgements}

None.

\section{Conflict of interest}

Author declares that there is no conflict of interest.

\section{References}

1. Shuryak I. Quantitative modeling of responses to chronic ionizing radiation exposure using targeted and non-targeted effects. PLOS ONE. 2017;12(4):e0176476.

2. Kamiya K, Ozasa K, Akiba S, et al. Long-term effects of radiation exposure on health. Lancet. 2015;386(9992):469-478.

3. Ochiai E. Hiroshima to Fukushima - Biohazards of radiation. 1st ed. Heidelberg: Springer; 2014. p. 155-178.

4. Fukunaga H, Yokoya A, Taki Y, et al. Radiobiological implications of Fukushima Nuclear Accident for personalized medical Approach. Tohoku J Exp Med. 2017;242(1):77-81.

5. Singh SR, Krishna K, Behera C, et al. Fatal radiation exposure due to careless disposal of Cobalt-60 from a university lab. J Indian Acad Forensic Med. 2013;35(3):281-284.

6. Krishnan M, Tennavan A, Seema S, et al. Acute Radiation-Induced Changes in Sprague-Dawley Rat Submandibular Glands: A Histomorphometric Analysis. World J Oncol. 2017;8(2):45-52. 
7. Moller AP, Barnier F, Mousseau TA. Ecosystems effects 25years after Chernobyl: pollinators, fruit set and recruitment. Oecologia 2012;170(4):1155-1165.

8. UNSCEAR. Scientific annex A: epidemiological studies of radiation and cancer. Effects of ionizing radiation, UNSCEAR Report 2006. New York, USA; 2008.

9. UNSCEAR. Scientific annex B: epidemiological evaluation of cardiovascular disease and other non-cancer disease following radiation exposure. Effects of ionizing radiation. UNSCEAR Report 2006. New York, USA; 2008.

10. Thompson MA. Maintaining a proper perspective of risk associated with radiation exposure. J Nucl Med Technol. 2001;29(3):137-142.

11. Moulder J, Medhora M. Advances in mitigation of injuries from radiological terrorism or nuclear accidents. Def Sci J. 2011;61(2):99-104.

12. Singh V, Gupta D, Arora R. NF- $\kappa$ B as a key player in regulation of cellular radiation responses and identification of radiation countermeasures. Discoveries. 2015;3(1):e35.

13. Rosen EM, Day R, Singh VK. New approaches to radiation Protection. Front Oncol. 2014;4:381.

14. Krishnan M, Iyer SR, Chakraborti KL, et al. Radiation Induced Xerostomia: Current Concepts and Future Trends. Def Life Sci J. 2017;2(3):256-263
15. Hofer M, Hoferova Z, Falk M. Pharmacological modulation of radiation damage. Does it exist a chance for other substances than hematopoietic growth factors and cytokines? Int J Mol Sci. 2017;18(7):e1385.

16. Weiss JF, Landauer MR. Radioprotection by antioxidants. Ann N Y Acad Sci. 2000;899:44-60.

17. Bhavani M, Tamizh Selvan G, Kaur H, et al. Dicentric chromosome aberration analysis using giemsa and centromere specific fluorescence in-situ hybridization for biological dosimetry: An inter-and intra-laboratory comparison in Indian laboratories. Appl Radiat Isot. 2014;92:85-90.

18. Semont A, Francois S, Mouiseddine M, et al. Mesenchymal stem cells increase self-renewal of small intestinal epithelium and accelerate structural recovery after radiation injury. Adv Exp Med Biol. 2006;585:19-30.

19. Ludlow JB, Davies-Ludlow LE, White SC. Patient Risk related to common dental radiographic examinations: The impact of 2007 ICRP regarding dose calculation. J Am Dent Assoc. 2008;139(9):1237-1243.

20. Aghamiri MR, Mortazavi SMJ, Tayebi M, et al. A Novel Design for production of efficient flexible lead-free shields against X-ray photons in diagnostic energy range. J Biomed Phys Eng. 2011;1(1):17-21. 